\title{
Author Correction: The Impact of Text Messaging on Medication Adherence and Exercise Among Postmyocardial Infarction Patients: Randomized Controlled Pilot Trial
}

\author{
Avinash Pandey $^{1 *}$; Alexis A Krumme ${ }^{2,3^{*}}, \mathrm{MS}$; Tejal Patel ${ }^{4 *}$, PharmD; Niteesh K Choudhry ${ }^{2,3^{*}}, \mathrm{MD}, \mathrm{PhD}$ \\ ${ }^{1}$ University of Western Ontario, London, ON, Canada \\ ${ }^{2}$ Division of Pharmacoepidemiology and Pharmacoeconomics, Department of Medicine, Brigham and Women's Hospital and Harvard Medical School, \\ Boston, MA, United States \\ ${ }^{3}$ Center for Healthcare Delivery Sciences, Department of Medicine, Brigham and Women's Hospital and Harvard Medical School, Boston, MA, United \\ States \\ ${ }^{4}$ School of Pharmacy, University of Waterloo, Waterloo, ON, Canada \\ *all authors contributed equally
}

\section{Corresponding Author:}

Niteesh K Choudhry, MD, PhD

Brigham and Women's Hospital and Harvard Medical School

1620 Tremont St Suite 3030

Boston, MA, 02120

United States

Phone: 16172780930

Fax: 16172328602

Email: nkchoudhry@bwh.harvard.edu

\section{Related Article:}

Correction of: http://mhealth.jmir.org/2017/8/e110

(JMIR Mhealth Uhealth 2019;7(4):e9254) doi: 10.2196/mhealth.9254

The corresponding author for "The Impact of Text Messaging on Medication Adherence and Exercise Among Postmyocardial Infarction Patients: Randomized Controlled Pilot Trial" (JMIR MHealth UHealth 2017 Aug 3;5(8):e110) has been changed from Alexis Krumme to Niteesh Choudhry, whose contact information is as follows:

Niteesh K Choudhry, MD, PhD

Brigham and Women's Hospital, Harvard Medical School

1620 Tremont Street, Suite 3030

Boston, MA, 02120

Phone: 16172780930
Fax: 16172328602

Email: nkchoudhry@bwh.harvard.edu

Additionally, middle initials have been added to the following authors' names:

\section{Alexis A Krumme \\ Niteesh K Choudhry}

The correction will appear in the online version of the paper on the JMIR website on April 3, 2019, together with the publication of this correction notice. Because this was made after submission to PubMed, PubMed Central, and other full-text repositories, the corrected article also has been resubmitted to those repositories.

Edited by G Eysenbach; this is a non-peer-reviewed article. Submitted 08.12.17; accepted 01.02.19; published 03.04.19.

Please cite as:

Pandey A, Krumme AA, Patel T, Choudhry NK

Author Correction: The Impact of Text Messaging on Medication Adherence and Exercise Among Postmyocardial Infarction Patients:

Randomized Controlled Pilot Trial

JMIR Mhealth Uhealth 2019;7(4):e9254

URL: https://mhealth.jmir.org/2019/4/e9254/

doi: 10.2196/mhealth.9254

PMID: 30943170 
(C)Avinash Pandey, Alexis A Krumme, Tejal Patel, Niteesh K Choudhry. Originally published in JMIR Mhealth and Uhealth (http://mhealth.jmir.org), 03.04.2019. This is an open-access article distributed under the terms of the Creative Commons Attribution License (https://creativecommons.org/licenses/by/4.0/), which permits unrestricted use, distribution, and reproduction in any medium, provided the original work, first published in JMIR mhealth and uhealth, is properly cited. The complete bibliographic information, a link to the original publication on http://mhealth.jmir.org/, as well as this copyright and license information must be included. 